\title{
Textos de la clerecía y de la lírica cor- tesana y la cuestión de «lo oficial» y «lo popular»
}

Este artículo no llegó a tiempo para ser in. cluido en el homenaje a Concepción Casado Lobato, pero a ella está dedicado.

La vieja Trotaconventos sabía bien su oficio y convenció a D. ${ }^{a}$ Endrina de que la acompañara a su casa. D. Melón, que ya estaba apercibido, pudo así, por fin, lograr sus deseos con la bella viuda. Juan Ruiz señala el momento de este desenlace con los siguientes versos:

Después fue de Santiago, otro día seguiente: a ora de mediodía, quando yanta la gente

$871 a b^{1}$

Nos da, así, una triple precisión temporal. A primera vista, el señalamiento que parece guardar una relación más estrecha con el episodio es el del mediodía. Es la hora del demonio meridiano, asociada por lo tanto con la sensualidad. Corresponde a 'sexta' en las horas canónicas y es muy significativo que en el rezo paródico de éstas por parte del clérigo lascivo, dice el Arcipreste:

Acabada ya la misa, rezas tanbién la sesta, que la vieja te tiene a tu amiga presta

$381 \mathrm{ab}$

Es decir, que se repite la misma situación e identificación temporal que en el episodio de $\mathrm{D}^{\mathrm{a}}$ Endrina. La precisión siguiente tampoco se presenta separada del sentido general del Libro si se atiende a las constantes del texto. Desde el principio se nos dice:

1 ARCIPReste De HitA, Libro de Buen Amor, ed. de J. Joset (Madrid, 1981), vol. I. Las citas pertenecen todas a esta edición. 
el mundo por dos cosas trabaja: la primera, por aver mantenençia; la otra cosa era por aver juntamiento con fenbra plazentera

$71 \mathrm{bcd}$

y luego veremos que el apetito sensual y la comida aparecen siempre emparejados. La consagración del dominio de ambos es la entrada triunfal de Carnal y Amor, llamados «emperadores»:

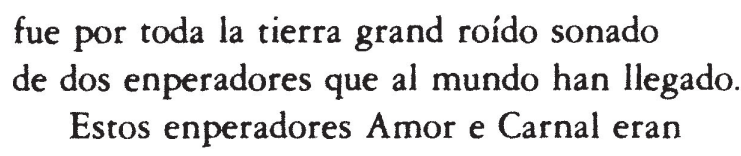

Estos enperadores Amor e Carnal eran

En cuanto a la referencia al santoral, puede tratarse de la fiesta del Apóstol, el 25 de julio, o quizá de la de Santiago el menor que se celebra el 1 de mayo ${ }^{2}$. Es decir, que en un caso el episodio se desarrollaría en pleno verano y en el otro, durante la primavera. Si fuera cierta esta segunda alternativa, caería por su peso la relación de una celebración de la maya con el significado erótico del episodio; pero también en el primer caso, por tratarse del momento central del verano, podría pensarse en un entrecruzamiento complementario con el mediodía, en un punto máximo de calor que connotaría el punto máximo del deseo.

En otras oportunidades he estudiado las funciones en el Buen Amor de las referencias a festividades litúrgicas, a los ciclos cósmicos y a las relaciones e influencias que se señalan respecto a la vida del hombre ${ }^{3}$. Considero que constituyen una dimensión sumamente significativa del texto, que motiva importantes vías de interpretación. En este caso particular, partiremos de la trilogía señalada para considerar su sentido y su procedencia.

De un modo u otro, las tres precisiones cronológicas configuran una triple evocación del erotismo. Y se trata de señalamientos temporales propios de la clerecía. No hablamos sólo del calendario litúrgico, sino de que los ciclos cósmicos - evolución del día, paso de las estacionesy su relación con la vida humana constituían un capítulo de la ciencia de «naturas». Respecto a esta relación, comentaba en uno de mis trabajos

2 J. Caro Baroja, La estación de Amor (Madrid, 1979), pp. 81-84.

3 S. Carrizo Rueda, "Los trabajos y los días del Arcipreste de Hita», Cuadernos Hispanoamericanos, 342 (1978), pp. $581-599$ y «Nuevas notas sobre ciclos temporales y cultura popular en la estructura del Libro de Buen Amom, RDTP, XLII (1987) pp. 75 94. 
dos citas del estudio de F. Rico sobre la General Estoria ${ }^{4}$. Vuelvo a ellas porque creo que aportan importantes fundamentos para el tema que estamos viendo.

«La historia de raíz verdaderamente cristiana abarca la tierra entera y se abre con la primera manifestación del obrar de Dios. Nada por otra parte puede resultarle extraño: para ella incluso la naturaleza es bistoria sagrada». (Subrayado mío.) ${ }^{5}$. Define a la extensa variedad de temas que constituyen la obra de Alfonso el Sabio «como conocimiento coherente de un universo jerarquizado como círculo que enlaza al hombre con el mundo y con Dios...»" 6 .

En aquella oportunidad relacioné estas aseveraciones con los motivos que decoran la tienda imperial, en una obra tan característica de la clerecía como el Libro de Alexandre?. Aparecen allí la narración bíblica de los orígenes del hombre, la alegoría de los meses, episodios protagonizados por los héroes clásicos, el mapamundi y las gestas del propio Alejandro ${ }^{8}$. No es difícil ver que conforman un compendio de "historia general» tal como la describe Rico y que dentro de ella está, casi al principio, la representación alegórica del ciclo anual y de la influencia de su transcurso en la naturaleza y en el quehacer de los hombres. Como es sabido, esta alegoría de los meses, basada fundamentalmente en los trabajos agrarios - aunque también es común la identificación de abril con el reinicio de las expediciones guerreras suspendidas en invierno- es un capítulo importante del arte medieval tanto literario como plástico.

No insistiré sobre tales aspectos porque creo que estos datos, fáciles de comprobar en cualquier obra que profundice en las summas del saber medieval, son suficientes para entrar en el aspecto central de la cuestión.

La división en que actualmente se insiste ente «cultura oficial» y "cultura popular» ${ }^{9}$ ha llegado a establecer dicotomías tajantes, realmente asombrosas. Una de ellas es atribuir cualquier referencia o reconocimiento de las fuerzas de la naturaleza a «lo carnavalesco», identificado de forma unívoca con la «cultura popular» la cual sería siempre una transgresión

\footnotetext{
4 Cf. «Nuevas notas...», p. 79.

5 F. Rico, Alfonso el Sabio y la «General Estoria» (Barcelona, 1972), p. 17.

6 Cf. op. cit., p. 142 y también 124 y 131.

7 Cf. art. cit., pp. 78-79.

8 Libro de Alexandre, ed. de F. MARCos MARín (Madrid, 1987), estrs. 2539-2595. La alegoría de los meses abarca las estrs. 2554-2566.

9 Se trata, como es sabido, de los estudios derivados de las propuestas de M. Bajtín, La cultura popular en la Edad Media y el Renacimiento. El contexto de Franfois Rabelais (Barcelona, 1974).
} 
de la «cultura oficial». Por oposición, claro, ésta ocultaría, negaría o ignoraría tales fuerzas. Así, dentro del tema que nos ocupa, M. de Lope llega a hacer la siguiente afirmación respecto a la alegoría de los meses en el Libro de Buen Amor:

Les images proprement carnavalesques du souffle fécondateur, du gonflement, transparaissent dans l'évocation de la croissance des céréales en avril et mai:
s. 1286 b
con los vientos que façe creçe trigo e çenteno.
s. 1288 a
el primero los panes e las frutas granava 10

Ver en estos dos versos imágenes "proprement carnavalesques» parece lindar ya con lo obsesivo.

Creo que precisamente la alegoría de los meses de Juan Ruiz, la del Alexandre, la de frescos o bajorrelieves y tantas otras que encontramos en obras medievales de procedencia culta, podría ser un tema que, estudiado en profundidad y sin preconceptos, podría ilustrar los numerosos puntos en común de la supuesta dicotomía cultural y lo poco rentable que resulta para acercarse a los productos artísticos de aquellos siglos. Hace unos años ya lo advertía G. Duby a través de una comparación con la división de la sociedad en tres órdenes -oradores, defensores, labradores - que manejaban los pensadores medievales:

La figura trifuncional era tan trivial que ninguno de estos escritores pensó en comentarla, en el destino que debía cumplir en su discurso teórico [...] no tenía ninguna relación con la realidad actual de la configuración social [...]. Estaba tan lejos de la realidad, como lo está por ejemplo, en la segunda mitad del siglo $\mathrm{xx}$, la bipartición ideológica que pretende convencernos de la existencia autónoma de una cultura popular $\stackrel{\text { I! }}{\text {. }}$

Respecto a lo relativo a la negación de las funciones de la naturaleza, hay que tener en cuenta que Bajtín elabora su teoría muy cerca todavía de las postrimerías de la era victoriana, durante la cual, la ocultación del sexo y todo cuanto pudiera sugerirlo sí era una cuestión de la cultura oficializada. Pero los textos medievales dan imágenes muy diferentes.

10 M. DE LOPE, Traditions populaires et textualité dans le «Libro de Buen Amon (Montpellier, 1984), p. 16, n. 18.

11 Cf. Los tres órdenes o lo imaginario del feudalismo (Barcelona, 1980), p. 145. Comentado por L. FUNES en «La literatura española medieval y la teoría literaria contemporánea: materiales para una discusión», I Congreso Argentino de Hispanistas (Bahía Blanca, 16-18 de octubre de 1986). 
Por ejemplo, en los Milagros de Nuestra Señora de Berceo, basados a su vez en una fuente latina eclesiástica, la Virgen, en sendos milagros, llega a arrebatar a los diablos las almas de un sacristán y de un romero que han muerto, condenados por el pecado de lujuria, pero que nunca habían dejado de ser devotos. Y en uno de los relatos más famosos de la colección, Santa María protege a la abadesa que ha quedado encinta, mientras deja avergonzadas a las otras monjas que se habían abandonado a la ira y al odio. Como en la gran mayoría de los textos medievales hispánicos, el tratamiento más severo es para los pecados del espíritu y no para los de la carne. Además, Berceo entra con toda naturalidad en una serie de pormenores físicos como las causas de la muerte del romero y las condiciones en que resucita - «Mas lo de la natura quanto que fo cortado, / Non li creció un punto, fincó en su estado. / [...] / Pora verter su agua fincóli el forado»- o las transformaciones del cuerpo de la abadesa - «Fol creciendo el vientre en contra las terniellas»-, y se refiere con gran ternura a su hijo - «cosiella mui fermosa»- que llega a ser un obispo ejemplar ${ }^{12}$. No creo que a nadie se le ocurra clasificar por esto a un autor y a una obra tan poco sospechosos de transgresiones a la ortodoxia, de «carnavalizantes» - aunque todo puede suceder-.

Volviendo al Buen Amor, algunos críticos que sostienen el modelo dicotómico, ante la irreductibilidad del Libro a cualquier clasificación rígida, han optado por calificar al Arcipreste de «mediador» entre los dos tipos de cultura que, según se sostiene, continuaban más allá del texto patentemente divorciadas. Es el caso de J. Joset ${ }^{13}$. Veamos cómo comenta la siguiente estrofa:

Estaba Don Carnal ricamente assentado, a mesa mucho farta, en un rico estrado, d'esas muchas vïandas era bien abastado; delante sí juglares como omne mucho onrado.

1095

$\mathrm{Y}$ dice al respecto Joset:

12 G. DE BERCEO, Milagros de Nuestra Señora, Milagro II, «El sacristán impúdico»; Milagro VII, «El romero de Santiago» -estrs. 192-193 y 211-213 - y Milagro XXI, «La abadesa encinta» -estrs. 508 y 533 -.

13 Autor de una valiosa edición del Libro -que es la que aquí utilizo- y fino crítico del mismo, en el artículo que comento cae en ciertas simplificaciones que demuestran los efectos empobrecedores de la aplicación del modelo dicotómico. 
Una vez más los juglares participan en el proceso carnavalesco, la gran fiesta pagana, las alegrías que revierten la jerarquía de las ideologías que atraviesan la sociedad. Son señales de la nobleza de Carnal, «omne mucho onrado», ocultado en tiempos normales por la cultura dominante. Manifiestan públicamente el derroche festivo de comida condenado por el ascetismo cristiano (Cuaresma) ${ }^{14}$.

El derroche festivo de comida, como reconoce el mismo crítico, era condenado por el ascetismo cristiano sólo en Cuaresma. En «tiempos normales», si bien la Iglesia predicaba una perfección que se apartaba de los goces mundanos y trataba de que fuera ejemplificada por las órdenes religiosas, no había ninguna prohibición de la celebración por la comida y las gentes de todos los estamentos banqueteaban tranquilamente, de acuerdo con los medios de cada cual. La identificación de lo celebratorio con la comida es un hecho de raíces tan profundas en la humanidad y, para no salirnos de nuestra área, en el mundo mediterráneo, que el Dios hecho Hombre da las primera señales de su divinidad en un banquete nupcial y finalmente instituye el culto central de su Iglesia en una Cena.

Cuando un hecho llega a estratos tan profundos ya nos aproximamos a los dominios de los arquetipos, al océano del inconsciente individual o colectivo, a la maraña de los instintos y de las percepciones primarias que necesitan para aflorar de imágenes simbólicas. Este espacio es por su mismo origen y constitución el de la plurivocidad, el de la superposición de sentidos.

Por ello precisamente, necesita para poder expresarse del lenguaje poético. Las particularidades de éste lo hacen el vehículo apropiado para transmitir todo aquello que, por su complejidad, resulta inaccesible para el lenguaje común, para la epistemología racional. El lenguaje poético es el único que puede reflejar sin traición las múltiples caras que coexisten en un mismo objeto, las contradicciones internas e irreductibles, el laberinto de toda interrelación, en suma, la polivalencia de los hechos del mundo. Tratar de aislar en una interpretación literaria un solo sentido es ya de por sí un acto de reduccionismo, pero si además ese sentido corresponde a un modelo teórico surgido de coordenadas espaciotemporales completamente diferentes, lo más probable es que sea erróneo.

Ya hemos visto respecto al cuerpo, por ejemplo, cómo Bajtín traslada a la época de Rabelais actitudes victorianas; pero desde un punto de vista más general, vemos que lo que en realidad ocurre es que todo su

I4 J. JOSET, «La Juglaría: mediadora ambigua de culturas en el Libro de Buen Amon, Actas del I Congreso Internacional de la Juglaresca (Madrid, 1986), pp. 317-322. 
modelo dialógico se resiente por querer oponer a lo largo de la historia un rígido y monolítico modelo cultural oficial y un proteico, exultante y rebelde modelo cultural popular. Si alguna vez se dio tal oposición no puede haber sido en otro momento que en el de los grandes imperios europeos del siglo XIX, que por una parte contaban con las estructuras y los medios aptos para producir y tratar de imponer sus modelos organicistas y, por otra, recibían el continuo hostigamiento de los herederos del romanticismo, cultores de las teorías del Folksgeist y de posturas anarquistas. Pero imaginar que las cosas pueden delimitarse con tanta facilidad en las sociedades medievales con su espíritu tribal, sus relaciones basadas en la sangre y en el concepto de parentesco, la guerra entre los señores y contra cualquier principio centralizador como el rey o el Papa como medio de vida, la economía agraria, el predominio de la oralidad, los restos del pensamiento animista, el primitivismo de las costumbres y la enorme dificultad de las comunicaciones, resulta una interpretación fuera de contexto.

En tales sociedades aparecen mezclados una serie de aspectos que luego se irán separando y combinando de otro modo en los siglos siguientes. Un caso ilustrativo es el de los poetas cortesanos que, con reyes y grandes magnates a la cabeza, lo mismo componían poemas en los que cantaban al ideal cortés del amor, a la Virgen o a las virtudes del buen caballero, que otros en los que campeaba lo grotesco, lo irreverente, lo obsceno y lo escatológico. Lo que importaba, más allá del contenido, eran los virtuosismos de la forma métrica y la agudeza de los juegos conceptistas. Tal es el caso de las cantigas de escarnio galaicoportuguesas o el de las sátiras personales de los cancioneros castellanos. Entre los autores hay figuras como Alfonso el Sabio o Jorge Manrique. Recordemos, por ejemplo, de este último, el poema dirigido a una beoda que tenía empeñado un brial en la taberna que se cierra con una letanía de nombres de vinos:

\footnotetext{
¡Oh, Beata Madrigal, ora pro nobis a Dios! ¡Oh, Santa Villa Real, señora, ruega por nos! ¡Santo Yepes, Santa Coca, rogad por nos al Señor, porque de vuestro dulzor no fallezca a la mi boca!
}

O bien, Un convite que hizo a su madrastra, en el cual el piadoso autor de las Coplas dice a esta señora: 


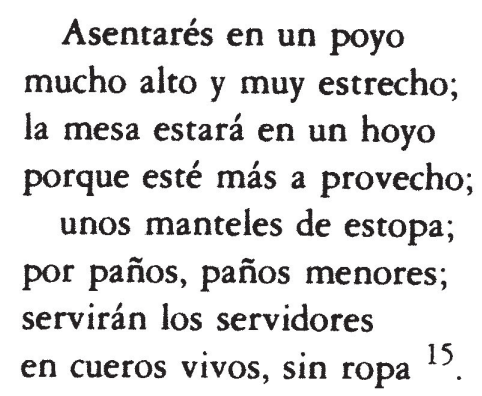

Es un magnífico ejemplo de lo que Bajtín califica de inversión carnavalesca del mundo, pero no se trata, por cierto, de una corriente literaria popular, sino de un género practicado por hombres de corte que se basaban en tradiciones cultas provenientes del sirventés provenzal. Tampoco era un tipo de poesía que circulara de forma más o menos subterránea, sino que compiladores como Alfonso de Baena en 1454 o Hernando del Castillo en 1511, lo incluyeron en sus Cancioneros junto a los otros géneros que se componían en los medios cortesanos. Fueron, por supuesto, los eruditos de tiempos posteriores los que consideraron oportuno ignorar estos poemas que hace relativamente poco han reingresado en la historia de la literatura.

En los citados poemas de Manrique aparecen la parodia de los signos de lo sagrado, la inversión vertical del espacio simbólico -compárese el «hoyo» con el estrado donde comían los grandes señores-, la bisemia que apunta a lo sexual - la dueña se sienta en un poyo estrecho y alto-, la manifestación del cuerpo - paños menores y servidores desnudos-. Es decir, todos aquellos rasgos que Bajtín ha estudiado en el Rabelais y que ha definido como «carnavalescos», profundizando, sin duda alguna, en los constituyentes de toda una parcela de la creatividad que a través del lenguaje, las imágenes o la mímica ha conformado una fértil tradición desde la menipea. Hasta aquí no podemos menos que congratularnos por la importancia del aporte del estudioso ruso. Pero inmediatamente se presentan los problemas. Uno son las extrapolaciones, como la que comentábamos al principio que considera «carnavalesco» todo lo que represente las fuerzas y funciones de la naturaleza. Otro es restringir la cultura popular a la fiesta y la rebelión, olvidando todo lo relacionado con el mundo del trabajo cotidiano y con tendencias conservadoras ${ }^{16}$. Un tercer problema es que se identifique en términos absolutos lo «carnavalizante» con un estrato social. A esta altura de las investigaciones sobre psicología, antropología y sobre cualquier ciencia

\footnotetext{
15 J. Manrique, Cancionero, ed. de A. Cortina (Madrid, 1960),

16 Acerca de estos aspectos hablo en mi citado artículo «Nueva notas...».
} 
de las que estudian al hombre, se impone el reconocimiento de que la tensión entre lo normativo y su transgresión es un fenómeno, antes que nada, humano. En algunas épocas es verdad que esto se ha tratado de negar, pero en otras se ha manifestado más libremente. La que llamamos Edad Media es una de estas últimas y hay que tomar también en cuenta la diversidad de los productos culturales de las distintas regiones, porque no son lo mismo, por ejemplo, la épica y las crónicas castellanas tan inclinadas a los detalles cotidianos y la épica y las crónicas francesas mucho más solemnes.

Una última reflexión es que el exceso de especialización nos está empujando en cierto modo hacia modelos simplificadores como el que nos ha ocupado. Se hacen cada día más necesarios los estudios interáreas que nos muestren un amplio contexto de los temas o autores que estudiamos y la actualización interdisciplinaria, para no continuar utilizando modelos que en sus propias disciplinas están siendo superados. Es, por ejemplo, el caso de la «cultura popular» de Gramsci cuestionada actualmente por no tomar en cuenta el dramatismo que implican sus componentes y el consiguiente dinamismo que ello origina ${ }^{17}$.

Volviendo a nuestro campo, lo específico es ese tipo determinado de discurso capaz de hacerse cargo de la multiplicidad de sentidos, de la ambigüedad, de la polivalencia. El mismo Bajtín instauró el estudio de la "polifonía» ${ }^{18}$. Como críticos, creo que son estos aspectos y el conflicto de su irreductibilidad lo que nos toca poner de manifiesto.

\section{SOFÍA CARRIZO RUEDA \\ Universidad Carólica Argentina \\ Facultad de Filosofía y Letras}

17 J. Halperín, «Diálogo con el antropólogo García Canclini», Clarín, Buenos Aires (17 de agosto de 1986).

18 Hay que tener en cuenta que, como es natural, el pensamiento de Bajtín fue evolucionando y sus teorías acerca de la novela muestran una concepción de la literaturidad' mucho más compleja. Cf. Esthétique et théorie du roman (Paris, 1978). Es interesante el dossier sobre su vida y obra presentado en Cuadernos Hispanoamericanos, n." 458 (1988). 
El modelo de M. Bajtín no puede ser utilizado sin una crítica previa que supere los condicionamientos de la época en que fue elaborado. En el presente artículo se sugieren reflexiones sobre diversos aspectos y se analizan textos de Berceo, de Juan Ruiz y de Jorge Manrique que demuestran la necesidad de deslindar «lo carnavalesco» de toda referencia social.

M. Bajtin's model can not be taken into account without a previous criticism that overcomes the dependences of the time in which it was elaborated. Some reflexions on diverse aspects are suggested in this article and some texts of Berceo, Juan Ruiz and Jorge Manrique which prove the need for defining the limits between the carnival-like aspect and every social reference, are analysed. 